\title{
Forelimb Movement Disorder in Rat Experimental Model
}

\author{
D. MAREŠOVÁ ${ }^{1}$, K. KOTKOVÁ ${ }^{2}$, P. KOZLER ${ }^{1}$, J. POKORNÝ ${ }^{1}$ \\ ${ }^{1}$ Institute of Physiology, First Faculty of Medicine, Charles University in Prague, Prague, Czech \\ Republic, ${ }^{2}$ Department of Rehabilitation Medicine of the First Faculty of Medicine of Charles \\ University and General Teaching Hospital in Prague, Prague, Czech Republic
}

Received March 25, 2019

Accepted July 4, 2019

Epub Ahead of Print October 25, 2019

\section{Summary}

Study of motor activity is an important part of the experimental models of neural disorders of rats. It is used to study effects of the CNS impairment, however studies on the peripheral nervous system lesions are much less frequent. The aim of the study was to extend the spectrum of experimental models of anterior limb movement disorders in rats by blockade of the right anterior limb brachial plexus with the local anesthetic Marcaine (Ma), or with aqua for injection administered into the same location (Aq) (with control intact group C). Two other groups with anterior limb movement disorders underwent induction of cellular brain edema by water intoxication (MaWI and AqWI). Results showed a lower spontaneous motor activity of animals in all experimental groups versus controls, and lower spontaneous motor activity of animals in the MaWI group compared to other experimental groups in all categories. There was no difference in spontaneous activity between the groups $\mathrm{Ma}, \mathrm{Aq}$ and AqWI. Our study indicates that alterations of spontaneous motor activity may result from the impaired forelimb motor activity induced by the anesthetic effect of Marcaine, by the volumetric effect of water, as a result of induced brain edema, or due to combination of these individual effects.

\section{Key words}

Peripheral nerve $\bullet$ Locomotor activity $\bullet$ Open field test $\bullet$ Rat

\section{Corresponding author}

D. Marešová, Institute of Physiology, First Faculty of Medicine, Charles University, Albertov 5, 12800 Prague 2, Czech Republic. E-mail: dana.maresova@lf1.cuni.cz
Spontaneous motor activity is an important parameter of experimental models of neural disorders of rats. It is currently studied by methods of the open field test, introduced into practice by Hall (1934). The spectrum of parameters studied in the open field test is extensive (Aragao et al. 2011, Russell et al. 2011, Šlamberová et al. 2013, Hrebíčková et al. 2014, Jandová et al. 2014, Kozler et al. 2014, Malinová-Ševčíková et al. 2014). Most of these studies was aimed at various experimental models of the CNS impairment in rodents. The use of open field test for examination of the peripheral nervous system lesions is much less frequent; in the PubMed database, only 7 papers dealing with this issue have been found (Bertelli and Mira 1993, Hasnie et al. 2007, Biazar et al. 2013, Vachon et al. 2013, Berger et al. 2014, Lyons et al. 2015, Murad and Ayoub 2015).

From the above reasons, one partial objectives of the study were to extend the spectrum of experimental models of peripheral motor disorders of forelimbs with the analysis of behavior in the open field test. The second aim was to offer to clinical disciplines dealing with motor impairment a new experimental model to study physiological and pathophysiological phenomena of the given disorders.

All experiments were approved by the Ethical Committee of the First Faculty of Medicine (Charles University in Prague) and were in agreement with the Guidelines of the Animal Protection Law of the Czech Republic and Guidelines for the treatment of laboratory animals EU Guidelines 86/609 / EEC.

For experiments, Wistar male rats of our own 
breed, with the body weight of 400-410g were used. Total of 40 rats were divided into five groups of 8 animals: Control group $\mathrm{C}$ consisted of intact animals; in the first experimental group (Ma), blockade of the right anterior limb brachial plexus with the local anesthetic Marcaine was done; in the second experimental group (Aq), instead of the anesthetics, aqua for injection was administered into the same location; in the third (MaWI) and the fourth (AqWI) groups, both interventions were done in rats with cellular brain edema (CE) induced by water intoxication (WI).

Surgery. Experimental interventions (applications of the solutions) were performed in spontaneously breathing rats under inhalation anesthesia

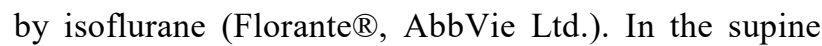
position with fixed and abducted limbs a needle was introduced in the skin fold of the right axilla to the shoulder girdle and one third of the dose was injected within three minutes into the inner side of the girdle and the other two thirds were injected above and below the girdle. In groups Ma and MaWI the nerve blockade was achieved by local anesthetic Marcaine in concentration of $0.5 \%$. Marcaine (bupivacaine hydrochloride Marcaine (C, AstraZeneca plc, www.medicines.org.uk/emc/ medicine/23926) is a local anesthetic of the amide type with medium latency and rapid onset of action, which brings prolonged reversible blockade of vegetative, sensitive and motor nerves and the cardiac conduction system. Marcaine blocks ionic flows across the membrane of nerve fibers, thus blocking the generation and propagation of action potentials.

The dose of Marcaine used to block the nerves was determined according the recommended dose for adult humans used in clinical practice, which has the maximum effect without and toxic side effects. For rats in our experiment (the body weight $400-410 \mathrm{~g}$ ) the dose was
$0.2 \mathrm{ml}$ of $0.5 \%$ Marcaine per a single injection.

Animals in the experimental groups $\mathrm{Aq}$ and AqWI received the same volume of Aqua for injection (B. Braun Medical), which is the common solvent for parenteral administration of water-soluble drugs and is also used as "sham solution" in rodent experimental models (Schulz et al. 2002, Klímová et al. 2014).

After the injection, inhalation anesthesia was terminated, and animals were left to awaken spontaneously. Recording started after the resumption of righting reflex, and the recovery of spontaneous locomotion. The time interval between the end of inhalation anesthesia and the start of testing was consistently 25 to 30 minutes.

Water intoxication was achieved by fractionized hyperhydration combined with administration of an antidiuretic drug desmopressin. This method is routinely used to induce experimental cellular brain edema and is described in details elsewhere (Olson et al. 1994, Yamaguchi et al. 1997, Silver at al. 1999, Manley et al. 2000, Vajda et al. 2000, Kozler and Pokorný 2003, Kozler et al, 2013, Kozler et al. 2017a, Kozler et al. 2017b, Kozler et al. 2018).

Open field test. To test horizontal locomotor activity - time spent in locomotion (s), distance travelled (m) and speed of locomotion $(\mathrm{m} / \mathrm{s})$ during one-hour interval, we used the system Laboras (Metris, B.V., Netherland). The system description and testing principles are described in details elsewhere (Aragao et al. 2011, Russell et al. 2011, Šlamberová et al. 2013, Jandová et al. 2014, Kozler et al. 2014, Hrebíčková et al. 2014, Malinová-Ševčíková et al. 2014).

Statistical evaluation. The results of all measurements were statistically evaluated using the tests of the GraphPad Prism program 6 (unpaired t test, the statistical significance was set at $5 \%$ ).
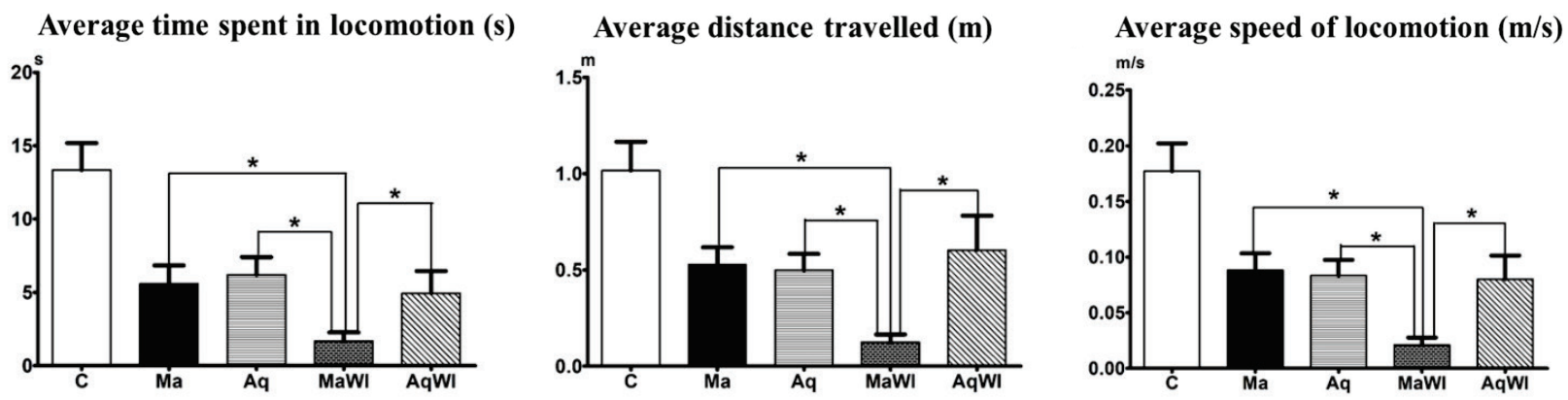

Fig. 1. Spontaneous motor activity of control and experimental animals. Legend: $C=$ Control group, $M a=M a r c a i n e ~ g r o u p, ~ A q=A q u a$ pro injectione group, MaWI = Marcaine after water intoxication group, AqWI = Aqua pro injectione after water intoxication group, $* p<0.05$. For simplicity; significance of differences between the control group and all experimental groups $(p<0.01)$ is not shown. 
The average values of all three motor activities were obtained by analyzing the first 10 second intervals from each of the six consecutive records during one hour of monitoring. The average activity values presented in the results thus represent the 60 -second average activity of all eight animals in each group. This method of analysis allows the Laboras software to exclude effects of the habituation phenomenon, which brings a decrease of motor activity in the second half of the monitoring (from 30 minutes onwards) as the animals become accustomed to the new environment (Prut et al. 2003).

Results given at Figure show a significantly lower spontaneous motor activity of animals in all experimental groups versus animals in the control group. Figure does not show the statistical significance of differences in motor activity between the control group and all experimental groups $(\mathrm{p}<0.01)$.

Results also show a significantly lower spontaneous motor activity of animals in the MaWI experimental group compared to other experimental groups in all categories. There was no significant difference in spontaneous activity between the experimental groups $\mathrm{Ma}, \mathrm{Aq}$ and $\mathrm{AqWI}$.

Behavioral observations have shown that rats are primarily "front-wheel drive" - front legs are predominantly used in the spontaneous locomotion. If their forelimbs are lifted above the floor, the rats are unable to walk on hind legs only. In the position on both hind legs - the rat is able to initiate gait with one leg while the other rotates on the ground or does few small steps backward or sideward. However, if hind legs are lifted above the floor - the position on both front legs the rat is able to walk immediately and cover a long distance in a position resembling driving the wheelbarrow ("wheelbarrow posture") (Schallert et al. 2003).

Results of our experiments indicate that disorders of the forelimb motor activity would significantly affect spontaneous movements of the whole animal. Monitoring and evaluation of spontaneous motor activity of animals was a priority in our work, so we did not study in detail the disorders of right front limb using standard tests of motor skills (Brooks and Dunnet 2009). Functional disorder of the right forelimb corresponded to the severe limitation of motor activity but the forelimb was not completely paralyzed.

In our work, the motor disorder of the right forelimbs was induced by blocking the brachial plexus by Marcaine or by application of aqua pro injectione into axilla; the same intervention into the forelimb motor activity was done also in animals with induced brain edema (Fig. 1). Comparing both methods for forelimb motor disorder induction, it is possible to conclude that the lowest spontaneous motor activity was found in animals with Marcaine blocade in animals with brain edema (MaWI group) (Fig. 1). The transient loss of peripheral nerve conductivity induced by Marcaine was augmented by the generally suppressive effect of brain edema.

The effect of cytotoxic brain edema plus peripheral neuropathy on the spontaneous locomotor activity of rats we have described in another work (Kozler et al. 2017).

The degree of reduction of the spontaneous motor activity of animals in experimental groups $\mathrm{Ma}, \mathrm{Aq}$ and AqWI was similar (no difference in parametrs of motor activity between these groups was found, Fig. 1).

Marcaine in Ma group_blocks the flow of ions across the membrane of nerve fibers, thus blocking the generation, propagation and conduction of action potentials.

In Aq group, a compressive neuropathy was induced by the volumetric effect of $0.2 \mathrm{ml}$ of water, that formed a fluid depot in the intimate proximity of brachial plexus. The fact that compression of nerve fibers brings impairment of their function was demonstrated in rats in experimental models - compression with a mini-clamp for 2 seconds or a compression by a minicuff inflated to $50 \mathrm{mmHg}$ resulted in an increased endoneural pressure and subsequent impairment of axonal conduction (Rydevik et al.1980, Igarashi et al. 2005). Manifestations of compression neuropathies, are also known in the clinical practice - nerve compression can be caused by a fluid, such as due to lymphedema (Ganel et al. 1979) or cyst (Sanchez et al. 2011).

Monitoring of spontaneous motor activities using the open field test revealed significantly lower activity in the $\mathrm{Ma}$ and $\mathrm{Aq}$ experimental groups versus animals of the control group. The activity reduction was comparable with no significant difference between both experimental groups (Fig. 1).

Open field test appears to be sufficiently sensitive method for registration and analysis of functional failure of a single forelimb but it is not specific enough to distinguish within the test period of 60 minutes the functional impairment induced by anesthetic from the compression effect of the solvent. In order to eliminate the volumetric effect, the period of recording should be extended, enabling water to be absorbed and reveal only 
Marcaine anesthetic effect. However, in our dose and concentration conditions it could last up to eight hours.

Nevertheless, we hypothesize that it was the anesthetic effect of Marcaine that reduced the motor activities of the animals of MA group, whereas it was the volumetric effect of aqua for injection which induced the same effect in the Aq group. As a proof we see the motor activity of animals in the experimental groups MaWI and AqWI - in animals with induced cellular brain edema. Their spontaneous motor activity was lower than those of the animals in the control group (Fig. 1). However, the spontaneous activity of the MaWI group was significantly lower than that of the animals in the AqWI group as well as in the Ma and Aq groups, among which there was no significant difference (see Figure). As the animals in the MaWI and AqWI experimental groups were those with cellular brain edema, it is probable that the very low motor activity of animals in the MaWI group results from the synergistic effect of the manipulated central nervous system (cellular edema and its general effect on cerebral function) and impaired peripheral nervous system (Marcaine anesthetic effect on brachial plexus fiber conductivity). If only the volumetric effect of the applied volume of fluid (Marcaine or Aqua for injection) would be behind the right anterior limb impairment, the spontaneous movement activity of animals in the AqWI group should be attenuated similarly to MaWI animals.
However, due to the absence of an anesthetic effect of Marcaine in animals in the AqWI group, the spontaneous motor activity of rats in this group is significantly less affected.

Our study indicates that the impaired anterior limb mobility and consequently the decreased spontaneous motor activity may result from Marcain's anesthetic effect, from the volumetric effect of the applied Aqua pro injectione, from the effect of induced cellular brain edema, or from combinations of these effects.

We believe that the results of our study will be also inspiring for some clinical disciplines such as neurorehabilitation. Modern neurorehabilitation should emphasize the well-defined, focused and reliably measurable procedures with specific indicators of the functional status (Daly et al. 2007). To advance clinical procedures, results of studies of physical activity of rats in experimental models appear to be essential (Kolb et al. 1991, Jones et al. 1999, Biernaskie et al. 2001)

\section{Conflict of Interest}

There is no conflict of interest.

\section{Acknowledgements}

Supported with grant Progres Q35/LF1.

\section{References}

ARAGÃO RDA S, RODRIGUES MA, DE BARROS KM, SILVA SR, TOSCANO AE, DE SOUZA RE, MANHÃESDE-CASTRO R: Automatic system for analysis of locomotor activity in rodents - a reproducibility study. J Neurosci Methods 15: 216-221, 2011.

BERGER ND, GADOTTI VM, PETROV RR, CHAPMAN K, DIAZ P, ZAMPONI GW: NMP-7 inhibits chronic inflammatory and neuropathic pain via block of Cav3.2 T-type calcium channels and activation of CB2 receptors. Mol Pain 6: 10-77, 2014.

BERTELLI JA, MIRA JC: Behavioral evaluating methods in the objective clinical assessment of motor function after experimental brachial plexus reconstruction in the rat. J Neurosci Methods 46: 203-208, 1993.

BIAZAR E, KESHEL SH, POUYA M: Efficacy of nanofibrous conduits in repair of long-segment sciatic nerve defects. Neural Regen Res 25: 2501-2509, 2013.

BIERNASKIE J, CORBETT D: Enriched rehabilitative training promotes improved forelimb motor function and enhanced dendritic growth after focal ischemic injury. $J$ Neurosci 21: 5272-5280, 2001.

BROOKS S, DUNNET S: Tests to assess motor phenotype in mice: a user's guide. Nat Rev Neurosci 10: 519-529, 2009.

DALY JJ, RUFF RL: Construction of efficacious gait and upper limb functional interventions based on brain plasticity evidence and model-based measures for stroke patients. Sci World J 20: 2031-2045, 2007.

GANEL A, ENGEL J, SELA M, BROOKS M: Nerve entrapments associated with postmastectomy lymphedema. Cancer 44: 2254-2259, 1979. 
HALL CS: Emotional behavior in the rat. I. Defecation and urination as measures of individual differences in emotionality. J Comp Psychol 18: 385-403, 1934.

HASNIE FS, WALLACE VC, HEFNER K, HOLMES A, RICE AS: Mechanical and cold hypersensitivity in nerveinjured $\mathrm{C} 57 \mathrm{BL} / 6 \mathrm{~J}$ mice is not associated with fear-avoidance- and depression-related behaviour. Br J Anaesth 98: 816-822, 2007.

HREBÍČKOVÁ I, MALINOVÁ-ŠEVČÍKOVÁ M, MACÚCHOVÁ E, NOHEJLOVÁ K, ŠLAMBEROVÁ R: Exposure to methamphetamine during first and second half of prenatal period and its consequences on cognition after long-term application in adulthood. Physiol Res 63 (Suppl 4): S535-S545, 2014.

IGARASHI T, YABUKI S, KIKUCHI S, MYERS RR: Effect of acute nerve root compression on endoneurial fluid pressure and blood flow in rat dorsal root ganglia. J Orthop Res 23: 420-424, 2005.

JANDOVÁ K, KOZLER P, LANGMEIER M, MAREŠOVÁ D, POKORNÝ J, RILJAK V: Influence of low-dose neonatal domoic acid on the spontaneous behavior of rats in early adulthood. Physiol Res 63 (Suppl 4): S521-S528, 2014.

JONES TA, CHU CJ, GRANDE LA, GREGORY AD: Motor skills training enhances lesion-induced structural plasticity in the motor cortex of adult rats. J Neurosci 19: 10153-10163, 1999.

KLÍMOVÁ A, SEIDLER ŠTANOGOVÁ P, HEISSIGEROVÁ J, SVOZÍLKOVÁ P, KUČERA T: Mycophenolate mofetil and cyclophosphamide treatments suppress inflammation intensity in an experimental model of autoimmune uveitis. Folia Biol (Praha) 60: 228-234, 2014.

KOLB B, GIBB R: Environmental enrichment and cortical injury: behavioural and anatomical consequences of frontal cortex lesions. Cereb Cortex 1: 189-198, 1991.

KOZLER P, POKORNÝ J: Altered blood-brain barrier permeability and its effect on the distribution of" Evans blue and sodium fluorescein in the rat brain applied by intracarotid injection. Physiol Res 52: 607-614, 2003.

KOZLER P, RILJAK V, POKORNÝ J: Both water intoxication and osmotic BBB disruption increase brain water content in rats. Physiol Res 62 (Suppl. 1): S75-S80, 2013.

KOZLER P, RILJAK V, JANDOVÁ K, POKORNÝ J: CT imaging and spontaneous behavior analysis after osmotic blood-brain barrier opening in Wistar rat. Physiol Res 63 (Suppl 4): S529-S534, 2014.

KOZLER P, MARESOVA D, POKORNY J: An experimental model of the "dual diagnosis": Effect of cytotoxic brain edema plus peripheral neuropathy on the spontaneous locomotor activity of rats. Neuro Endocrinol Lett 38: 408-414, 2017a.

KOZLER P, MAREŠOVÁ D, POKORNÝ J: Methylprednisolone modulates intracranial pressure in the brain cellular edema induced by water intoxication. Physiol Res 66 (Suppl 4): S511-S516, $2017 \mathrm{~b}$.

KOZLER P, MAREŠOVA D, POKORNÝ J: Cellular brain edema induced by water intoxication in rat experimental model. Neuro Endocrinol Lett 39: 209-218, 2018.

LYONS DN, KNIFFIN TC, ZHANG LP, DANAHER RJ, MILLER CS, BOCANEGRA JL, CARLSON CR, WESTLUND KN: Trigeminal Inflammatory Compression (TIC) injury induces chronic facial pain and susceptibility to anxiety-related behaviors. Neuroscience 295: 126-138, 2015.

MALINOVÁ-ŠEVČIIKOVÁ M, HREBÍČKOVÁ I, MACÚCHOVÁ E, NOVÁ E, POMETLOVÁ M, ŠLAMBEROVÁ $\mathrm{R}$ : Differences in maternal behavior and development of their pups depend on the time of methamphetamine exposure during gestation period. Physiol Res 63 (Suppl 4): S559-S572, 2014.

MANLEY GT, FUJIMURA M, MA T, NOSHITA N, FILIZ F, BOLLEN AW, CHAN P, VERKMAN AS: Aquaporin4 deletion in mice reduces brain edema after acute water intoxication and ischemic stroke. Nat Med 6: 159-163, 2000.

MURAD H, AYUOB N: Co-Administration of Pioglitazone Improves Fluoxetine's Antinociceptive, Neuroprotective, and Antidepressant Effects in Chronic Constriction Injury in Rats. Pain Physician 18: 609-620, 2015.

OLSON JE, EVERS JA, BANKS M: Brain osmolyte content and blood-brain barrier water permeability surface area product in osmotic edema. Acta Neurochir Suppl 60: 571-573, 1994.

PRUT L, BELZUNG C: The open field as a paradigm to measure the effects of drugs on anxiety-like behaviors: a review. Eur J Pharmacol 463: 3-33, 2003. 
RUSSELL KL, KUTCHKO KM, FOWLER SC, BERMAN NE, LEVANT B: Sensorimotor behavioral tests for use in a juvenile rat model of traumatic brain injury: assessment of sex differences. J Neurosci Methods 199: 214-222, 2011.

RYDEVIK B, NORDBORG C: Changes in nerve function and nerve fibre structure induced by acute, graded compression. J Neurol Neurosurg Psychiatry 43: 1070-1082, 1980.

SANCHEZ JE, CONKLING N, LABROPOULOS N: Compression syndromes of the popliteal neurovascular bundle due to Baker cyst. J Vasc Surg 54: 1821-1829, 2011.

SCHALLERT T, WOODLEE MT: Brain-dependent movements and cerebral-spinal connections: key targets of cellular and behavioral enrichment in CNS injury models. J Rehabil Res Dev 40: 9-17, 2003.

SILVER SM, SCHROEDER BM, BERNSTEIN P, STERNS RH: Brain adaptation to acute hyponatremia in young rats. Am J Physiol 276: R1595-1599, 1999.

SLAMBEROVÁ R, MACÚCHOVÁ E, NOHEJLOVÁ-DEYKUN K, SCHUTOVÁ B, HRUBÁ L, ROKYTA R: Gender differences in the effect of prenatal methamphetamine exposure and challenge dose of other drugs on behavior of adult rats. Physiol Res 62 (Suppl 1): S99-S108, 2013.

SCHULZ C, WIECZOREK I, RESCHKE K, LEHNERT H: Effects of intracerebroventricularly and intraperitoneally administered growth hormone on body weight and food intake in fa/fa Zucker rats. Neuropsychobiology 45 : 36-40, 2002.

VACHON P, MILLECAMPS M, LOW L, THOMPSOSN SJ, PAILLEUX F, BEAUDRY F, BUSHNELL CM, STONE LS: Alleviation of chronic neuropathic pain by environmental enrichment in mice well after the establishment of chronic pain. Behav Brain Funct 7: 9-22, 2013.

VAJDA Z, PROMENEUR D, DÓCZI T, SULYOK E, FRØKIAER J, OTTERSEN OP, NIELSEN S: Increased aquaporin-4 immunoreactivity in rat brain in response to systemic hyponatremia. Biochem Biophys Res Commun 270: 495-503, 2000.

YAMAGUCHI M, YAMADA T, KINOSHITA I, WU S, NAGASHIMA T, TAMAKI N: Impaired learning of active avoidance in water-intoxicated rats. Acta Neurochir Suppl 70: 152-154, 1997. 